This is the Accepted Author Manuscript of the publication

\title{
Imaging of brain TSPO expression in a mouse model of amyotrophic lateral sclerosis with 18F-DPA-714 and micro-PET/CT.
}

\section{Gargiulo S ${ }^{1,2}$, Anzilotti $S^{3}$, Coda AR', Gramanzini M1,2, Greco A ${ }^{2,4}$, Panico $M^{1}$, Vinciguerra $A^{5}$, Zannetti $A^{1}$, Vicidomini $C^{1}$, Dollé $F^{6}$, Pignataro $G^{5}$, Quarantelli $M^{1}$, Annunziato $L^{3,5}$, Brunetti $A^{2,4}$, Salvatore $M^{3}$, Pappatà $S^{1}$.}

\footnotetext{
${ }^{1}$ Institute of Biostructure and Bioimaging, National Research Council, Via T. De Amicis 95, 80145, Naples, Italy.

${ }^{2}$ Ceinge Biotecnologie Avanzate s. c. a r. l., Via G. Salvatore 486, 80145, Naples, Italy. ${ }^{3}$ IRCCS SDN, Via E. Gianturco 113, 80143, Naples, Italy.

${ }^{4}$ Department of Advanced Biomedical Sciences, University "Federico II", Via S. Pansini 5, 80131, Naples, Italy.

${ }^{5}$ Division of Pharmacology, Department of Neuroscience, Reproductive and Dentistry Sciences, School of Medicine, University "Federico II", Via S. Pansini 5, 80131, Naples, Italy.

${ }^{6}$ CEA, Institute for Biomedical Imaging, 4 Place du Général Leclerc, 91401, Orsay, France.
}

Corresponding author:

S. Pappatà

sabina.pappata@ibb.cnr.it

Published in: Eur J Nucl Med Mol Imaging. 2016 Jan 27.

Doi: $10.1007 / \mathrm{s} 00259-016-3311-y$

The final publication is available at http://link.springer.com/article/10.1007\%2Fs00259-016-3311-y 
S. Gargiulo ${ }^{1,2 \S}$, S. Anzilotti ${ }^{3 \S}$, A.R.D. Coda ${ }^{1}$, M. Gramanzini ${ }^{1,2}$, A. Greco ${ }^{4,2}$, M. Panico ${ }^{1}$ A. Vinciguerra $^{5}$, A. Zannetti ${ }^{1}$, C. Vicidomini ${ }^{1}$, F. Dollé ${ }^{6}$, G. Pignataro ${ }^{5}$, M. Quarantelli ${ }^{1}$, L. Annunziato $^{5,3}$, A. Brunetti ${ }^{4,2}$, M. Salvatore ${ }^{3}$, S. Pappatà ${ }^{1^{*}}$

Imaging of brain TSPO expression in a mouse model of amyotrophic lateral sclerosis with ${ }^{18} \mathrm{~F}$ DPA-714 and micro-PET/CT.

${ }^{1}$ Institute of Biostructure and Bioimaging, National Research Council, Via T. De Amicis 95, 80145, Naples, Italy

${ }^{2}$ Ceinge Biotecnologie Avanzate s. c. a r. 1., Via G. Salvatore 486, 80145, Naples, Italy

${ }^{3}$ IRCCS SDN, Via E. Gianturco 113, 80143, Naples, Italy

${ }^{4}$ Department of Advanced Biomedical Sciences, University "Federico II", Via S. Pansini 5, 80131, Naples, Italy

${ }^{5}$ Division of Pharmacology, Department of Neuroscience, Reproductive and Dentistry Sciences, School of Medicine, University “Federico II”, Via S. Pansini 5, 80131, Naples, Italy

${ }^{6}$ CEA, Institute for Biomedical Imaging, 4 Place du Général Leclerc, 91401, Orsay, France

* Corresponding Author: Sabina Pappatà, sabina.pappata@ibb.cnr.it; Tel.: + 390812203414 / +39 3666115326; fax: +390812203498

$\S_{\text {These authors contributed equally }}$

Acknowledgement: The research leading to these results has received funding from the European Union's Seventh Framework Programme (FP7/2007-2013) under grant agreement nº HEALTH-F22011-278850 (INMiND). 


\section{Abstract}

Purpose To evaluate the feasibility and sensitivity of ${ }^{18} \mathrm{~F}-\mathrm{DPA}-714$ for the study of microglial activation in brain and spinal cord of transgenic SOD1 ${ }^{\mathrm{G} 93 \mathrm{~A}}$ mice using high resolution PET/CT and to evaluate the Iba1 and TSPO expression with immunohistochemistry.

Methods Nine symptomatic SOD1 ${ }^{\mathrm{G} 93 \mathrm{~A}}$ mice (age: $117 \pm 12.7$ days; clinical score range: $\left.1-4\right)$ and five WT SOD1 control mice (age: $108 \pm 28.5$ days) underwent ${ }^{18}$ F-DPA-714 PET/CT. SUV ratios were calculated by normalizing cerebellar (rCRB), brainstem (rBS), motor cortex (rMCX) and cervical spinal cord (rCSC) activity to that of the frontal association cortex (FrA). Two WT SOD1 and six symptomatic SOD ${ }^{\mathrm{G} 93 \mathrm{~A}}$ mice were studied by immunohistochemistry.

Results In the symptomatic SOD $1^{\mathrm{G} 93 \mathrm{~A}}$ mice, the $\mathrm{rCRB}$, rBS and $\mathrm{rCSC}$ were increased as compared to WT SOD1, with a statistically significantly difference in the $\operatorname{rBS}(2.340 \pm 0.784$ vs $1.576 \pm 0.287$, $\mathrm{p}=0.014)$. Immunofluorescence studies showed that TSPO expression was increased in the trigeminal, facial, ambiguus and hypoglossal nuclei, as well as in the spinal cord, of symptomatic $\mathrm{SOD} 1^{\mathrm{G} 93 \mathrm{~A}}$ mice and was colocalized with increased Ibal staining.

Conclusion Increased ${ }^{18} \mathrm{~F}-\mathrm{DPA}-714$ uptake can be detected with high resolution PET/CT in the brainstem of transgenic SOD1 ${ }^{\mathrm{G} 93 \mathrm{~A}}$ mice, a region known to be a site of degeneration and increased microglial activation in ALS, in agreement with the increased TSPO expression in brainstem nuclei showed by immunostaining. Therefore, ${ }^{18}$ F-DPA-714 PET/CT might be a suitable tool to evaluate microglial activation in the SOD $1^{\mathrm{G} 93 \mathrm{~A}}$ mouse model.

Keywords: SOD $1{ }^{\mathrm{G} 93 \mathrm{~A}}$, TSPO, PET/CT, ${ }^{18}$ F-DPA-714, mice 


\section{Introduction}

Amyotrophic lateral sclerosis (ALS) is a fatal neurodegenerative disease characterized by a progressive loss of motor neurons (MN) in the spinal cord, brainstem nuclei and motor cortex. Degeneration of $\mathrm{MN}$ results in muscle impairment, weakness and spasticity, and respiratory failure, leading to death within approximately 3-5 years from symptoms onset [1-4]. Most cases of ALS are sporadic, but approximately $20 \%$ of familial ALS and 5\% of apparently sporadic disease are associated with the gene encoding the enzyme $\mathrm{Cu}^{2+} / \mathrm{Zn}^{2+}$ superoxide dismutase (SOD1) [2, 4]. The mechanisms underlying neurodegeneration in ALS are multifactorial, involving a complex interplay between molecular and genetic pathways [1, 4]. Neuroinflammation, and specifically activated microglia are neuropathological features of ALS and might play a role in MN degeneration and disease progression [5-9]. Post-mortem studies in human beings showed astrocytosis and microgliosis in the motor cortex, the motor nuclei of the brainstem, the anterior horn of the spinal cord, and along the corticospinal tract $[6,9,10]$. Interestingly, the transgenic mouse overexpressing a mutant form of the human $\mathrm{Cu}^{2+} / \mathrm{Zn}^{2+}$ superoxide dismutase, SOD1 ${ }^{\mathrm{G} 93 \mathrm{~A}}$ [11] also displayed, ex vivo, similar inflammatory responses seen in ALS patients, including activated microglia, astrogliosis and infiltrating lymphocytes accompanying MN injury in spinal cord and brainstem [5, $6,9,12-14]$. Moreover, in more advanced stages, inflammatory reactions were also detected in motor cortex $[15,16]$ and cerebellar nuclei [17]. Therefore, SOD ${ }^{\mathrm{G} 93 \mathrm{~A}}$ mice provide a useful and relevant tool for investigating neuroinflammation. Assessment of glial activation can be performed in vivo non invasively using Positron Emission Tomography (PET) and selective radioligands for $18 \mathrm{kDa}$ translocator protein (TSPO), formerly known as the peripheral benzodiazepine receptor (PBR) [18-20]. Under physiological conditions, relatively low levels of TSPO are found in the central nervous system (CNS), but in response to neuroinflammation its expression increases markedly in activated glial cells [19-21]. Using PET and ${ }^{11} \mathrm{C}-\mathrm{PK} 11195$ Turner and colleagues reported in a pioneering study increased binding in the motor cortex, pons, dorsolateral prefrontal 
cortex and thalamus in a group of ALS patients [22]. Using second-generation TSPO radioligands, characterized by higher specific binding, additional support was provided to these findings [23, 24]. Post-mortem human studies suggest that increased binding of both $\left[{ }^{3} \mathrm{H}\right](R)$-PK11195 and $\left[{ }^{3}\right.$ H]DAA1106 overlapped most prominently with CD68-labeled activated microglia, compared with GFAP-labeled astrocytes, at least in the motor cortex [25]. To our knowledge, no in vivo studies have demonstrated that increased TSPO expression in the brain and in the spinal cord of ALS might be related to microglial activation. The use of animal models is of relevance for validation of PET-TSPO radiotracers, in particular when combined with immunohistochemistry. This complementary approach may allow characterization of histopathological changes underlying in vivo imaging. Moreover, it could allow detection and monitoring of neuroinflammation from the pre-symptomatic stage and the evaluation of the effects of therapies. The aim of this proof-ofconcept study was to investigate CNS neuroinflammation, in particular microglial activation, in symptomatic transgenic SOD $1{ }^{\mathrm{G} 93 \mathrm{~A}}$ mice, both in vivo with $\mathrm{PET} / \mathrm{CT}$ and ${ }^{18} \mathrm{~F}-\mathrm{DPA}-714$, a promising radioligand for the study of TSPO sites [23, 26-30] recently validated in normal mice [31], and ex vivo with immunohistologic analysis. The results of this study will highlight the feasibility and the sensitivity of micro-PET and ${ }^{18}$ F-DPA-714 in detecting increases in TSPO expression in the brain and in the spinal cord of the SOD1 ${ }^{\mathrm{G} 93 \mathrm{~A}}$ mouse model, and will provide additional information on the relationships between TSPO expression and microglial activation underlying PET- ${ }^{18}$ F-DPA-714 changes.

\section{Materials and methods}

\section{Animals and ethical statement}

All experimental procedures have complied with the European Communities Council directives (2010/63/EU) and national regulations (D.L. 116/92) and were performed in accordance with National Institutes of Health $(\mathrm{NIH})$ recommendations. The present study was approved by the Animal and Care Committee of the University of Naples "Federico II" and by the Italian Ministry 
of Health (authorization number 1/2014-01-15). All efforts were made to minimize animal suffering and the number of animals necessary to produce reliable results. Mice were purchased from Jackson laboratories (Bar Harbor, ME, USA) via Charles River (Calco, LC, Italy) and were housed in group cages under standard conditions with free access to food and water. Experiments were carried out in adult male transgenic hemizygous B6SJL-Tg[SOD1*G93A]1Gur/J mice (SOD1 ${ }^{\text {G93A; }}$; Stock Number 002726), expressing high copy number $(\approx 29)$ of the mutant human SOD1 allele with a Gly93Ala substitution [11, 32], that are characterized by survival times of $128.9 \pm 9.1$ days. Transgenic hemizygous B6SJL-Tg(SOD1)2Gur/J (WT SOD1, Stock Number 002297), carrying the normal allele of human SOD1 gene, served as controls for the B6SJL-Tg[SOD1*G93A]1Gur/J (Stock Number 002726) strain, as it is reported that WT SOD1 mice express the same level of SOD1 protein than SOD1 ${ }^{\mathrm{G} 93 \mathrm{~A}}$ and do not develop motor neurons degeneration [11].

\section{Animal care, disease onset and progression analysis}

To determine disease onset and progression, mice were monitored three times a week starting at 50 days of age using a clinical score system (CS) described by Solomon and colleagues [33], with a scale from 0 to 5 as follows: $0=$ no evidence of disease; $1=$ shaking or splaying of the hindlimbs when suspended by the tail; $1.5=$ weakness in one hindlimb; 2 = change in gait: toes curl under at least twice during walking, or any part of foot is dragging along cage bottom/table; $2.5=$ extreme weakness in one hindlimb; 3 = extreme weakness in both hindlimbs; $3.5=$ functional paralysis in one hindlimb; 4 = functional paralysis in both hindlimbs but can right themselves in less than $20 \mathrm{~s}$ after being placed on their side; $5=$ cannot right themselves to sternum within $20 \mathrm{~s}$ after being placed on their sides (endpoint). SOD ${ }^{\mathrm{G} 93 \mathrm{~A}}$ mice with advanced symptoms of ALS (CS $\geq 2$ ) had a palatable source of hydration and energy (gel diet energy, Safe) placed on bedding and electrolyte balanced solutions were provided parenterally. Body weight and body condition score (BCS, scale from 0 to 5) were evaluated three times a week, as described elsewhere [33]. Because of ethical considerations mice were euthanized after reaching a score of 4 according to the guidelines for 
preclinical testing and colony management [34].

Radiochemical synthesis

All reagents and solvents were purchased from Sigma-Aldrich Corporation. Briefly, DPA-714 (N,N-diethyl-2-(2-(4-(2-fluoroethoxy)phenyl)-5,7-dimethylpyrazolo[1,5-a]pyrimidin-3-

yl)acetamide) as reference compound and its tosyloxy derivative (toluene-4-sulfonic acid 2-[4 (3diethylcarbamoylmethyl-5,7-dimethyl-pyrazolo-[1,5-a] pyrimidin-2-yl)-phenoxy]-ethyl-ester) as precursor for labeling with fluorine-18 were resynthesized in our laboratories according to the literature procedures [35]. No-carrier-added fluorine-18 (half-life 109.8 minutes) was produced via the $\left[{ }^{18} \mathrm{O}(\mathrm{p}, \mathrm{n}){ }^{18} \mathrm{~F}\right]$ nuclear reaction by irradiation of a $2-\mathrm{mL}\left[{ }^{18} \mathrm{O}\right]$ water $(97 \%$ enriched, $\mathrm{ABX}$, Radeberg, Germany) target on an General Electric MINItrace cyclotron (10 MeV proton beam) and the aqueous radioactive solution was then transferred to the appropriate hot cell. Typical production of ${ }^{18} \mathrm{~F}$-fluorine at the end of a $25 \mu \mathrm{Ah}, 60 \mathrm{~min}(12.5 \mu \mathrm{Ah})$ irradiation was $16-17 \mathrm{GBq}(732-769$ $\mathrm{mCi}$ ). Fluorine-18 was then trapped in a chromafix PS-HCO3- cartridge and after elution with $0.550 \mathrm{~mL} \mathrm{~K} \mathrm{CO}_{3}(6 \mathrm{mg} / \mathrm{mL})$ the ${ }^{18} \mathrm{~F}$-fluorine was collected in a vessel containing Kryptofix-222 dissolved in $\left.1 \mathrm{~mL} \mathrm{CH} \mathrm{CH}_{3} \mathrm{CN} 222: 15 \mathrm{mg} / \mathrm{mL}\right) .{ }^{18} \mathrm{~F}$-DPA-714 was labeled by ${ }^{18} \mathrm{~F}$-fluoride (half-life 109.8 minutes) starting from the corresponding precursor using a tosyloxy-for- fluorine nucleophilic aliphatic substitution according to slight modifications of procedures already reported $[35,36]$. Specific activity at the end of synthesis and radiochemical purity of ${ }^{18}$ F-DPA-714 obtained within 90 minutes of radiosynthesis (HPLC purification and SepPak-based formulation included) were $300 \mathrm{GBq} / \mu \mathrm{mol}$ and $\mathrm{N}>99 \%$ respectively.

In vivo imaging

Nine symptomatic SOD1 ${ }^{\mathrm{G} 93 \mathrm{~A}}$ mice aged from 98 to 137 days (mean \pm SD: $117 \pm 12.75$ ) with CS ranging from 1 to $4(\operatorname{CS~} 1: n=3$; $\operatorname{CS~} 1.5: n=1 ; \operatorname{CS} 2: n=2 ; \operatorname{CS~} 3: n=1 ; \operatorname{CS} 4: n=2 ;$ median=2) and five congenic controls WT SOD1 aged from 71 to 137 days (mean \pm SD: $108 \pm 28.5$ days) were studied. High-resolution PET/CT (GE Healthcare eXplore Vista, resolution: $1.8 \mathrm{~mm}$ FWHM/200 
$\mu \mathrm{m}$; sensitivity: $4.2 \%$ ACS) were performed under inhalant anesthesia (isoflurane $2 \%$, oxygen 2 L/min). Images were acquired in dynamic mode (frames sequence: 6 x 5 minutes) over 30 minutes starting 20 minutes after tail vein injection of 5.55-7.00 MBq (SRA: $200-800 \mathrm{GBq} / \mu \mathrm{mol}$ ) of ${ }^{18} \mathrm{~F}$ DPA-714, and were processed using a 2D FORE/3D OSEM iterative algorithm (voxel size: 0.3875 x $0.3875 \times 0.775 \mathrm{~mm}^{3}$ ) including random, scatter, dead time, and decay correction. Counting rates were converted to Standardized Uptake Values (SUV=tissue activity (MBq/cc)/[injected dose $(\mathrm{MBq}) /$ body weight $(\mathrm{g})])$. PET frames acquired between 20 and 50 minutes were summed and used for data analysis. Regions of interest (ROIs) were manually defined on summed axial PET images based on PET/CT fusion images, using the Paxinos and Franklin's mouse brain atlas for guidance [37]. ROIs were placed on the cerebellum $\left(6 \mathrm{~mm}^{2}\right)$, brainstem $\left(2.5 \mathrm{~mm}^{2}\right)$, the upper part of cervical spinal cord $\left(1.5 \mathrm{~mm}^{2}\right)$, motor frontal cortex and frontal association cortex $\left(2 \mathrm{~mm}^{2}\right)$, over at least 3 consecutive slices using Osirix Imaging Software 5.8.5 (Pixmeo, Bermex, Switzerland). ROIs analysis on the thoracic and lumbar tracts of the spinal cord was excluded because these regions could be affected by partial volume effects due to the small size of these structures and the high ${ }^{18} \mathrm{~F}$ uptake in the surrounding tissues, such as lung and kidneys [31]. For each brain region, ${ }^{18} \mathrm{~F}-\mathrm{DPA}-$ 714 SUV values were calculated by pooling the ROIs defined over consecutive slices. SUV ratios were calculated by normalizing cervical spinal cord (rCSC), cerebellar (rCRB), brainstem (rBS), and motor cortex (rMCX) activity to that of the frontal association cortex (FrA). This normalization was performed in order to reduce the between-subject variability in radiotracer uptake. The FrA was used for normalization because this region is unaffected in $\mathrm{SOD} 1^{\mathrm{G} 93 \mathrm{~A}}$ mice as suggested by our in vivo and post-mortem data, showing no significant difference of SUV values between SOD1 ${ }^{\mathrm{G} 93 \mathrm{~A}}$ and WT SOD1 mice nor post-mortem evidence of increased TSPO expression or microglial activation (see below). 
Tissue processing and immunohistochemistry

Two controls WT SOD1 and six symptomatic SOD1 ${ }^{\mathrm{G} 93 \mathrm{~A}}$ mice, two with CS of 2 and 2.5 respectively and four with CS of 4 (range of CS: 2-4; median: 4) were studied using immunofluorescence analysis. All underwent PET from 1 to 9 days before euthanasia (mean \pm SD: $5 \pm 3$ days) except one SOD $1^{\mathrm{G} 93 \mathrm{~A}}$ with CS of 2 . Mice were deeply anesthetized (isoflurane $4 \%$, oxygen $2 \mathrm{~L} / \mathrm{min}$ ), and transcardially perfused with about $30 \mathrm{ml}$ ice-cold phosphate buffered saline (0.1 M PBS), followed by $60 \mathrm{ml}$ of $4 \%$ paraformaldehyde in saline solution. Brains and spinal cords were then dissected out and post-fixed overnight in $4 \%$ paraformaldehyde at $4{ }^{\circ} \mathrm{C}$ and cryoprotected in PBS containing 30\% sucrose for $48 \mathrm{~h}$ at $4^{\circ} \mathrm{C}$. Brains and spinal cords were sectioned frozen on a sliding cryostat at $40 \mu \mathrm{m}$ thickness and free floating sections were incubated with blocking solution $(0.5 \%$ milk, $10 \% \mathrm{FBS}, 1 \% \mathrm{BSA})$ for $1.30 \mathrm{~h}$ [38]. Sections were than incubated overnight at $4^{\circ} \mathrm{C}$ with the following primary antibodies: rabbit monoclonal anti-PBR (1:500, Novus Biologicals) and mouse monoclonal anti-Iba1 (ionized calcium binding adapter molecule 1, 1:1000, Abcam).

Ibal is a protein that in humans is encoded by the AIF1 gene. The AIF1 gene is located within a segment of the major histocompatibility complex class III region. It has been shown that this gene is highly expressed in testis, spleen, brain, lung, and kidney [39]. Among brain cells, the Ibal gene was specifically expressed in microglia. Upon activation of microglia due to inflammation, expression of Ibal is upregulated allowing the discrimination between physiological and activated microglia [40]. Iba1 is a $17-\mathrm{kDa}$ EF hand protein that is specifically expressed in macrophages/microglia and is upregulated during the activation of these cells [41]. Ibal expression is up-regulated in microglia following nerve injury, central nervous system ischemia, and several other brain diseases [40]. Many articles showed that Iba1 protein is expressed in microglia alone both in cultured brain cells and in the brain, respectively. In a mixed cell culture of embryonic rat brain, immunohistochemical analysis revealed that the localization of Ibal protein is restricted to microglia and it was not detectable in neurons, astroglia, or oligodendrocytes [40]. 
Subsequently, the sections were incubated with the corresponding fluorescent-labeled secondary antibodies (Alexa 488/Alexa 594-conjugated anti-mouse/anti-rabbit IgGs). Fluorescence was examined using a confocal microscope (Zeiss LSM 700). Single images were taken with an optical thickness of $0.7 \mu \mathrm{m}$, at a resolution of $1024 \times 1024$ and at $40 \mathrm{X}$ of magnification. In double-labeled sections, the pattern of immunoreactivity for both antigens was identical to that seen in singlestained material. Control double immunofluorescence staining entailed the replacement of the primary antisera with normal serum (data not shown). To minimize a possible cross-reactivity between IgGs in double immunolabeling experiments, the full complement of secondary antibodies was maintained, but the primary antisera were replaced with normal serum or only one primary antibody was applied (data not shown). In addition, the secondary antibodies were highly preadsorbed to the IgGs of numerous species. Tissue labeling without primary antibodies was also tested to exclude autofluorescence. No specific staining was observed under these control conditions, thus confirming the specificity of the immunosignals. The following regions were studied: spinal cord, brainstem motor nuclei, cerebellum, motor cortex and prefrontal cortex. In one of the symptomatic SOD $1^{\mathrm{G} 93 \mathrm{~A}}$ mice with $\mathrm{CS}$ of 4 only motor cortex and spinal cord were available for immunohistochemistry. For the exact identification of frontal association cortex and brainstem (oro)motor nuclei, Paxinos and Franklin's mouse brain atlas [37] was used. The sections of each area were analyzed within the following stereotaxic coordinates, expressed in $\mathrm{mm}$ anterior to the bregma for frontal association cortex (3.20-2.58) and posterior to the bregma for trigeminal motor nucleus (4.96-5.34); for facial nucleus (5.68-6.48); for ambiguus nucleus (6.70-8.00); for hypoglossal nucleus (7.00-7.12). The spinal cord was divided into cervical (C1-C4), thoracic (T8T11), and lumbar (L1-L4) regions.

\section{Statistical analysis}

Descriptive statistic for body weight, BCS and CS was provided in both SOD $1^{\mathrm{G} 93 \mathrm{~A}}$ and WT SOD mice and for survival in SOD $1{ }^{\mathrm{G} 93 \mathrm{~A}}$ mice. ${ }^{18} \mathrm{~F}-\mathrm{DPA}-714 \mathrm{SUV}$ values of FrA and regional SUV ratios were presented as mean \pm SD. Statistical analysis was performed to test clinical and ${ }^{18}$ F-DPA-714 
SUV data using the software package SPSS (version 11, SPSS, Chicago, Illinois, USA). Non parametric Mann-Whitney test was used to compare ${ }^{18}$ F-DPA-714 SUV values of FrA, and rCSC, $\mathrm{rCRB}, \mathrm{rBS}$ and $\mathrm{rMCX}$ between SOD1 ${ }^{\mathrm{G} 93 \mathrm{~A}}$ and WT SOD mice. Sample size required to reach a $5 \%$ significance with a $80 \%$ power was estimated for Mann-Whitney test [42]. Non parametric Spearman's rank correlation coefficient was used to test correlation of age and clinical score with $\mathrm{rCSC}, \mathrm{rCRB}, \mathrm{rBS}$ and $\mathrm{rMCX}$ values in $\mathrm{SOD} 1^{\mathrm{G} 93 \mathrm{~A}}$ mice. The level of significance was set at $\mathrm{P}$ $\leq 0.05$.

\section{Results}

Clinical score, body weight and body condition score

The SOD1 ${ }^{\mathrm{G} 93 \mathrm{~A}}$ mice became symptomatic from 95 days of age (mean $\pm \mathrm{SD}$ : $102.8 \pm 7.04$; range: 95 110). All SOD $1^{\mathrm{G} 93 \mathrm{~A}}$ mice which underwent in vivo PET studies showed a worsening in CS (ranging from score 1 to 4 ) and BCS (ranging from score 3 to 2) as the disease progressed. All WT SOD1 controls remained healthy $(\mathrm{CS}=0 ; \mathrm{BCS}=3)$ at the endpoint ages of their matched $\mathrm{SOD} 1^{\mathrm{G} 93 \mathrm{~A}}$ mice. The average body weight of SOD $1^{\mathrm{G} 93 \mathrm{~A}}$ mice was significantly lower than WT SOD1 from the age of 14 weeks (mean \pm SD: $26.55 \pm 2.49$ vs $31.29 \pm 1.84 \mathrm{~g}$ respectively, $\mathrm{p}=0.027$ ) onwards, with the body weight difference increasing with disease progression (Supplementary Fig.1). Average survival time of the SOD $1^{\mathrm{G} 93 \mathrm{~A}}$ mice was $121 \pm 12$ days.

${ }^{18}$ F-DPA-714 uptake in CNS

Visual assessment of PET images revealed a clear increase of ${ }^{18} \mathrm{~F}-\mathrm{DPA}-714$ uptake in the brainstem and in the spinal cervical tract of symptomatic SOD1 ${ }^{\mathrm{G} 93 \mathrm{~A}}$ mice as compared to WT SOD1, while the anterior cerebral regions did not display any evident difference (Fig. 1). The average SUV values of FrA in SOD1 ${ }^{\mathrm{G} 93 \mathrm{~A}}$ mice were not significantly different from those of WT SOD mice $(0.207 \pm 0.090$ and $0.225 \pm 0.105$, respectively; $p=0.787)$. SUV ratios measured in different CNS regions of the $\mathrm{SOD} 1^{\mathrm{G} 93 \mathrm{~A}}$ and WT SOD1 mice are summarized as mean $\pm \mathrm{SD}$ in Table 1 and Fig. 2. Statistical analysis revealed that the average $\mathrm{rBS}$ values were significantly increased in 
symptomatic SOD1 ${ }^{\mathrm{G} 93 \mathrm{~A}}$ mice compared with WT SOD1 controls $(\mathrm{p}=0.014)$. The rCSC mean values were also increased by $59 \%$ in symptomatic SOD $1^{\mathrm{G} 93 \mathrm{~A}}$ mice as compared to WT SOD1 controls, but this raise did not reach significance $(\mathrm{p}=0.053)$. There was no significant difference in the $\mathrm{rCRB}$ and $\mathrm{rMCX}$ values between symptomatic SOD ${ }^{\mathrm{G} 93 \mathrm{~A}}$ mice and WT SOD1 controls (rCRB: $\mathrm{p}=0.162$; rMCX: $\mathrm{p}=0.162$ ). In symptomatic SOD $1^{\mathrm{G} 93 \mathrm{~A}}$ mice, CS showed a statistically significant correlation with age in days $(\mathrm{R}=0.786, \mathrm{p} \leq 0.05)$, whereas there was no significant correlation between $\mathrm{CS}$ and ${ }^{18}$ F-DPA-714 ratios.

\section{Immunohistochemistry}

Iba1 positive cells increased in the trigeminal, facial, ambiguus and hypoglossal nuclei of the SOD $1^{\text {G93A }}$ mice with CS of 4 compared to WT SOD1 controls (Fig. 3), and showed morphological changes such as large cell body and shortening of cellular processes. In the facial nucleus, in particular (Fig. 4), Ibal positive cells showed a dramatic morphological change, mainly characterized by enlarged shape and short cellular processes. Moreover, TSPO expression was clearly increased in brainstem nuclei, and double immunohistochemical analysis revealed that it colocalized with Iba1 positive cells, mainly with large body ones. Ibal and TSPO immunoreactivities were also increased in SOD $1^{\mathrm{G} 93 \mathrm{~A}}$ mice with CS 2-2.5 compared to WT SOD1 controls, although to a lesser extent than SOD1 ${ }^{\mathrm{G} 93 \mathrm{~A}}$ mice with CS of 4. Similarly, TSPO expression colocalized with Iba1 immunoreactivity in most nuclei. In the trigeminal nucleus, the increase in Iba1 positive cells was quite abundant, while the TSPO immunoreactivity was less marked than that observed in mice with CS of 4. Increased immunolabeling was found in the cerebellum and in the motor cortex of two different mice with CS of 4. However, no increase in Ibal and TSPO immunoreactivities was detected in the frontal association cortex of SOD $1^{\mathrm{G} 93 \mathrm{~A}}$ mice compared to WT SOD1 controls (Supplementary Fig. 2). In the cervical and thoracic spinal cord (Fig. 5a and b), Iba1 signal study showed that Iba1 was higher in SOD ${ }^{\mathrm{G} 93 \mathrm{~A}}$ mice with CS of 4 compared to WT SOD1 controls. Moreover, TSPO expression showed a marked increase in SOD1 ${ }^{\mathrm{G} 93 \mathrm{~A}}$ mice with CS of 4, whereas when CS was 2.5 it was very low. Finally, in lumbar spinal cord (Fig. 5c), Iba1 
immunolabeling showed high levels of expression in SOD $1^{\mathrm{G} 93 \mathrm{~A}}$ mice independently from the clinical score. In fact, it was similar in SOD1 ${ }^{\mathrm{G} 93 \mathrm{~A}}$ mice with CS of 2.5 or 4 . Conversely, TSPO immunolabeling was lower in SOD1 ${ }^{\mathrm{G} 93 \mathrm{~A}}$ mice with $\mathrm{CS}$ of 2.5 compared to those with $\mathrm{CS}$ of 4.

\section{Discussion}

The results of this proof of concept study suggest that a significant increase in ${ }^{18} \mathrm{~F}$-DPA-714 uptake can be measured with high resolution PET/CT in the brainstem of symptomatic SOD ${ }^{\mathrm{G} 93 \mathrm{~A}}$ mice, a model of ALS. Moreover, immunostaining showed that TSPO expression is increased in brainstem nuclei and colocalized with Ibal immunoreactivity, suggesting that increased microglial activation might underly at least in part the increased brainstem ${ }^{18} \mathrm{~F}$-DPA-714 uptake. In contrast, the uptake of ${ }^{18}$ F-DPA-714 and the TSPO and Ibal immunolabeling were not significantly increased in transgenic mice over-expressing the non-mutated wild-type human SOD1. To our knowledge, this is the first report in which PET and TSPO radiotracer were applied to SOD1 ${ }^{\mathrm{G} 93 \mathrm{~A}}$ mouse model of ALS and were combined with immunohistochemistry for the evaluation of TSPO expression and microglial activation.

There is a growing body of evidence from post-mortem [13, 14, 43] and in vivo MRI studies combined with histopathology [44-48] suggesting that selective brainstem nuclei are the site of degenerative changes and/or strong inflammatory reaction in SOD1-ALS transgenic mice. In particular, the trigeminal, facial, and ambiguus nuclei were found consistently affected, while the hypoglossal nucleus was altered in some reports [14, 46-48] but uninvolved in others [43, 44]. The reasons why motor neurons are particularly susceptible to injury in the presence of mutations that affect ubiquitously distributed proteins, such as SOD1, are not completely understood [1]. Putative mechanisms include a toxic gain of function of the SOD1 enzyme, conformational instability and misfolding of the SOD1 peptide [1,4]. Interestingly, brainstem nuclei more severely affected in advanced stage SOD1 ${ }^{\mathrm{G} 93 \mathrm{~A}}$ mice have higher levels of human mutant SOD1 accumulation in this preclinical model, possibly modulating differential formation of protein aggregates associated to 
motor neuron degeneration $[49,50]$. Both astrogliosis and microgliosis appeared simultaneously to the degenerative changes either post- or pre-symptomatically and increased substantially with time [48]. The earliest changes were found at 60 days for astrocytes and 80 days for microglia [48]. Interestingly, in this latter report the authors suggested that astrocyte and microglia activation, and not only vacuolization, might have contributed to T2-weighted changes found in motor brainstem nuclei of SOD1 ${ }^{\mathrm{G} 93 \mathrm{~A}}$ mice, since no detectable change in $\mathrm{T} 1$ signal intensity was observed. These MRI changes cannot however provide specific information on neuroinflammatory cellular alterations. The results of our study revealed that direct evaluation of brainstem gliosis might be provided in vivo with PET and ${ }^{18}$ F-DPA-714 in a mouse model of ALS. Although specific brainstem nuclei cannot be identified with PET, due to the lower spatial resolution in comparison to MRI, the results of our combined PET/immunohistochemistry studies suggested that increased Iba1 expression in the trigeminal, facial, ambiguus and hypoglossal nuclei might underlay increased ${ }^{18} \mathrm{~F}$ DPA-714 brainstem binding measured in vivo in symptomatic SOD1 ${ }^{\mathrm{G} 93 \mathrm{~A}}$ mice. Our study in fact showed for the first time that increased TSPO expression was also found in the same brainstem nuclei and colocalized with Ibal activated microglia with large cell bodies and short cellular processes. These changes were particularly marked in the facial and ambiguus nuclei, and in more severely clinically affected mice (CS of 4), while they were not found in WT SOD1 mice of similar age. These findings are in line with the sustained and progressive increase of microglial activation previously reported in brainstem nuclei in symptomatic SOD1 ${ }^{\mathrm{G} 93 \mathrm{~A}}$ mice [48]. Moreover, our findings are in agreement with previous human studies reporting increased [11C](R)-PK11195 PET signal in the pons of ALS patients [22], and with a more recent study showing increased PBR28 uptake in the brainstem of individuals with bulbar-onset ALS [24]. This latter finding (observed only in 3 patients) deserves further investigation and suggests that TSPO expression might be related to ALS clinical phenotype. Interestingly, our data are also in line with a recent PET- ${ }^{18}$ FFDG study [51] showing increased relative glucose metabolism in the midbrain of patients with ALS, possibly related to gliosis. The SOD1 ${ }^{\mathrm{G} 93 \mathrm{~A}}$ mouse model was used extensively to study the 
degeneration of the spinal cord; nonetheless, previous evidence and our results suggest that the occurrence of brainstem degeneration is reminiscent of ALS and that this model might be of relevance for the study of bulbar-onset ALS phenotype [13].

We did not find significant increase of ${ }^{18} \mathrm{~F}-\mathrm{DPA}-714$ binding in the cerebellum and in the motor cortex. Previous studies suggested that similarly to humans, SOD1-ALS transgenic mice also showed more widespread degenerative and/or inflammatory changes involving other brain regions than spinal cord and brainstem including the cerebellum [17, 44], and the motor cortex $[15,16,52]$. Decreased T2 signal intensity was reported by Zang and colleagues [44] in the cerebellum, suggesting the presence of atrophy, while degeneration and/or inflammation was found in the motor cortex but mainly at late stages [44]. Using a combination of anatomic, cellular, transgenic labeling, and newly available neuronal subtype-specific molecular analyses, Ozdinler and colleagues [16] showed that degeneration of corticospinal motor neurones occurs since the early pre-symptomatic stages in hSOD1G93A mice, while activated microglia and astrocytes mainly occur at late stages of disease and are not restricted to motor cortex. Thus, our findings are in line with mild changes reported in these regions of SOD $1^{\mathrm{G} 93 \mathrm{~A}}$ mice. Detection of these changes presumably lies beyond the resolution of the PET technique. Interestingly, increased Ibal and TSPO expression were found in the motor cortex of one symptomatic SOD $1^{\mathrm{G} 93 \mathrm{~A}}$ mouse and in the cerebellum of another one, both studied at CS of 4 (data not shown). Further studies are required to address this interesting issue.

Despite in our symptomatic SOD ${ }^{\mathrm{G} 93 \mathrm{~A}}$ mice the average ${ }^{18} \mathrm{~F}-\mathrm{DPA}-714$ binding was increased by $59 \%$ in the cervical tract of the spinal cord (CSC region) compared to WT SOD1 mice, this raise was not significant. This suggests a certain variability in the individual binding and/or low accuracy of in vivo PET measurement in this region likely due partial volume effects and/or low animal number. Given the relatively small size of some of the sampled structures, as compared to the resolution of the scanner, partial volume effect may have contributed to scattering of the data, hindering possible significant differences, especially in the cervical spinal cord. On the other hand, 
the significant increases in the brainstem that we found can be hardly explained by such a phenomenon. Given the current lack of general consensus on a satisfactory partial volume correction method for small animal PET [53], especially when spill-in from "hot" extracerebral structures is present, we did not attempt to include this processing step in our analysis. In particular for ${ }^{18}$ F-DPA-714, given the high uptake of the tracer in some of the extracerebral (e.g. Harderian and salivary glands, nasopharyngeal lymphoid tissue [54], and paravertebral (e.g. nucal muscles) structures, partial volume effect correction need to model also these structures, to properly be performed [55].

In contrast, our immunohistological results clearly showed increased TSPO expression in cervical, thoracic and lumbar spinal tracts, that colocalizes with Ibal immunoreactivity, has a trend for a stronger expression in the cervical and lumbar tracts and, similarly to the brainstem, in mice with higher clinical score. These results are in accordance with previous post-mortem findings of increased microglial reactivity in lumbar and/or cervical-thoracic spinal cord of mutant SOD $1^{\mathrm{G} 93 \mathrm{~A}}$ mice $[14,56,57]$ and transgenic hmSOD1G93A rats [58]. Moreover, they demonstrated that increased TSPO expression is present in the spinal cord of symptomatic SOD ${ }^{\mathrm{G} 93 \mathrm{~A}}$ mice. This suggests that PET and TSPO radioligands could be used for the study of spinal cord microglial activation in ALS patients.

We did not find any significant correlation between the CS and regional ${ }^{18}$ F-DPA-714 binding, in particular in the brainstem of symptomatic SOD $1^{\mathrm{G} 93 \mathrm{~A}}$ mice. To our knowledge, no study has evaluated the correlation between clinical severity and microglial activation in the brainstem of SOD1 ${ }^{\mathrm{G} 93 \mathrm{~A}}$ mice. In a previous study, high significant correlation was reported in SOD $1{ }^{\mathrm{G} 93 \mathrm{~A}}$ mice among increased $\mathrm{T} 2$ values in brainstem nuclei and behavioural deficit (exploratory behaviour, locomotor activity) [45]. Previous PET studies in ALS patients showed a significant correlation between Upper Motor Neuron (UMN) score and increased TSPO radiotracer binding in the motor cortex [22-24], but not with disease duration. The small number of animals and the lack of more appropriate clinical evaluation specifically focused on "bulbar" signs might in part explain 
our results. Future studies are required to specifically address this issue.

Overall the results of our study suggest that increased ${ }^{18} \mathrm{~F}-\mathrm{DPA}-714$ binding measured with PET in the brainstem of symptomatic SOD $1^{\mathrm{G} 93 \mathrm{~A}}$ mice is due to increased TSPO expression in activated microglia, at least at later clinical stages, and further emphasize the valuable role of TSPO radiotracers as in vivo markers of microglia activation associated with neurodegenerative diseases like ALS. Microglial cell activation has been implicated in the pathogenesis of several neurodegenerative conditions, including ALS [5-7, 59]. Neuroinflammation, and in particular microglial activation, may mediate both beneficial and harmful effects within diseased area of the CNS in ALS $[6,7]$. Thus, a better understanding of glial-neuronal interactions might be useful for future development of more efficient therapies. We cannot exclude that astrocytes activation might also underlay increased TSPO expression and ${ }^{18} \mathrm{~F}-\mathrm{DPA}-714$ uptake found in our mice, since strong GFAP immunostaining was also reported in the brainstem nuclei and/or spinal cord of transgenic SOD $1^{\mathrm{G} 93 \mathrm{~A}}$ mice $[9,13,14,56,57]$. The evaluation of astroglial activation was not the aim of this study. However, preliminary results (data not shown) in one symptomatic SOD ${ }^{\mathrm{G} 93 \mathrm{~A}}$ mouse with a CS of 4 revealed an increased GFAP immunoreactivity in brainstem nuclei and spinal cord without a clear colocalization with TSPO immunolabeling. Our data are in line with post-mortem findings showing the prevalent correlation between increased binding of two TSPO PET radiotracers (H3PK11195 and H3-DAA 1106) and cd11 immunostaining in the primary motor cortex of patients with ALS [25], and with previous reports suggesting that TSPO is highly expressed in activated microglia, and to a lesser extent in reactive astrocytes in other CNS disorders [19, 20]. Further studies, aimed at addressing the specific contribution of astrocytes activation to the increased TSPO expression in brainstem nuclei and spinal cord, are needed to solve this point.

The main limitation of this proof of concept study is the relatively small number of mice. Thus, caution is required in the interpretation of the results. Estimated sample sizes per group ranged from 9 for cervical spinal cord to 18 for cerebellum and motor cortex [42]. Further studies in a larger group of animals are needed to assess the sensitivity of PET- ${ }^{18}$ F-DPA-714 in detecting changes 
occurring in the brainstem and in other CNS regions of SOD1 ${ }^{\mathrm{G} 93 \mathrm{~A}}$ mice at different stages of disease, including pre-symptomatic stage, and to evaluate whether these changes have clinical relevance.

We failed to measure in vivo with PET significant changes of ${ }^{18} \mathrm{~F}-\mathrm{DPA}-714$ uptake in the spinal cord. This suggests that PET and ${ }^{18}$ F-DPA-714 are not sensitive enough for detecting microglial activation and increased TSPO expression in mice, at least at the cervical level. Future studies should assess whether micro-PET with higher resolution, or the development of adequate methods for PVE correction might improve the sensitivity and accuracy.

Finally, in this study we did not attempt to quantify the immunohistochemical data, thus limiting the possibility to carry out a quantitative correlation analysis with ${ }^{18}$ F-DPA-714 uptake, as only a visual evaluation was performed. Future studies are required to address this specific issue.

In conclusion, despite the limitations mentioned above, our study suggests that micro-PET and ${ }^{18} \mathrm{~F}$ DPA-714 might be a useful tool for the study of microglial activation in the SOD1 ${ }^{\mathrm{G} 93 \mathrm{~A}}$ mouse model. Future studies are required to evaluate the sensitivity of this technique for studying disease progression and the effects of innovative therapies. In this respect, it should be stressed that in SOD $1^{\mathrm{G} 93 \mathrm{~A}}$ mice a different clinical phenotype (e.g. disease onset and progression) could be related to different genetic background [60]. These authors in a combined MRI and histological study showed that increased T2 values in cranial motor nuclei, associated with significant tissue vacuolization, were more marked in $\mathrm{SOD} 1^{\mathrm{G} 93 \mathrm{~A}}$ mice with $\mathrm{C} 57 \mathrm{BL} / 6 \mathrm{~J}$ genetic background than in those with 129S2/SvHsd genetic background, despite these latter exhibit a faster disease progression. These observations suggest that the prognostic value of an in vivo marker should be tested and validated in different animal models. Although neuroinflammatory markers were not evaluated in the study of Caron and colleagues [60], further studies are required to characterize microglial activation and PET- ${ }^{18}$ F-DPA-714 uptake in other animal models with different disease progression and severity in view of monitoring the effects of therapies or developing new therapeutical strategies. 
Nevertheless, the results of this study strengthen the high relevance of combined preclinical PET and immunohistochemistry studies for the cellular characterization of the PET signal in vivo.

\section{Compliance with Ethical Standard}

Funding: The research leading to these results has received funding from the European Union's Seventh Framework Programme (FP7/2007-2013) under grant agreement n HEALTH-F2-2011278850 (INMiND).

Conflict of interest: The authors declare that they have no conflict of interest.

Ethical approval: All applicable international, national, and/or institutional guidelines for the care and use of animals were followed. 


\section{References}

1. Ferraiuolo L, Kirby J, Grierson AJ, Sendtner M, Shaw PJ. Molecular pathways of motor neuron injury in amyotrophic lateral sclerosis. Nat Rev Neurol. 2011; 7: 616-30.

2. Cleveland DW, Rothstein JD. From Charcot to Lou G erhring: deciphering selective motor neuron death in ALS. Nat Rev Neurosci. 2001; 2: 806-19.

3. Van Damme P, Robberecht W. Recent advances in motor neuron disease. Curr Opin Neurol. 2009; 22: 486-92.

4. Kiernan MC, Vucic S, Cheah BC, Turner MR, Eisen A, Hardiman O, Burrell JR, Zoing MC. Amyotrophic lateral sclerosis. Lancet. 2011; 377: 942-55.

5. McGeer PL, McGeer EG. Inflammatory processes in amyotrophic lateral sclerosis. Muscle \& Nerve. 2002; 26: 459-70.

6. Appel SH, Zhao W, Beers DR, Henkel JS. The microglial-motoneuron dialogue in ALS. Acta Myol. 2011; 30: 4-8.

7. Philips T, Robberecht W. Neuroinflammation in amyotrophic lateral sclerosis: role of glial activation in motor neuron disease. Lancet Neurol. 2011;10:253-63.

8. Brettschneider J, Toledo JB, Van Deerlin VM, Elman L, McCluskey L, Lee VM, Trojanowski JQ. Microglial activation correlates with disease progression and upper motor neuron clinical symptoms in amyotrophic lateral sclerosis. PLoS One. 2012; 7: e39216.

9. Evans MC, Couch Y, Sibson N, Turner MR. Inflammation and neurovascular changes in amyotrophic lateral sclerosis. Mol Cell Neurosci. 2013; 53: 34-41.

10. Kawamata T, Akyyama H, Yamada T, McGeer PL. Immunologic Reactions in Amyotrophic Lateral Sclerosis Brain and Spinal Cord Tissues. American Journal of Pathology. 1992; 140: 691-707.

11. Gurney ME, Pu H, Chiu AY, Dal Canto MC, Polchow CY, Alexander DD, Caliendo J, Hentati A, Kwon YW, Deng HX, Chen W, Zhai P, Sufit RL, Siddique T. Motor neuron 
degeneration in mice that express a human $\mathrm{Cu}, \mathrm{Zn}$ superoxide dismutase mutation. Science $1994 ; 264: 1772-5$.

12. Henkel JS, Engelhardt JI, Siklos L, Simpson EP, Kim SH, Pan T, Goodman JC, SiddiqueT, Beers DR, Appel SH. Presence of dendritic cells, MCP-1, and activated microglia/macrophages in amyotrophic lateral sclerosis spinal cord tissue. Ann Neurol. 2004; 55: 221-35.

13. Ferrucci M, Spalloni A, Bartalucci A, Cantafora E, Fulceri F, Nutini M, Longone P, Paparelli A, Fornai F. A systematic study of brainstem motor nuclei in a mouse model of ALS, the effects of lithium. Neurobiol Dis. 2010; 37: 370-83.

14. Leichsenring A, Linnartz B, Zhu XR, Lubbert H, Stichel CC. Ascending neuropathology in the CNS of a mutant SOD1 mouse model of amyotrophic lateral sclerosis. Brain Res 2006; 1096: $180-95$.

15. Petrik MS, Wilson JM, Grant SC, Blackband SJ, Tabata RC, Shan X, Krieger C, Shaw CA. Magnetic resonance microscopy and immunohistochemistry of the CNS of the mutant SOD murine model of ALS reveals widespread neural deficits. Neuromolecular Med. 2007;9:21629.

16. Ozdinler PH, Benn S, Yamamoto TH, Güzel M, Brown RH Jr, Macklis JD. Corticospinal motor neurons and related subcerebral projection neurons undergo early and specific neurodegeneration in hSOD1 ${ }^{\mathrm{G} 93 \mathrm{~A}}$ transgenic ALS mice. J Neurosci. 2011;31:4166-77.

17. Chung YH, Joo KM, Lee YJ, Shin DH, Cha CI. Reactive astrocytes express PARP in the central nervous system of SOD(G93A) transgenic mice. Brain Res. 2004;1003:199-204.

18. Banati RB. Visualizating microglial activation in vivo. Glia. 2002; 40: 206-17.

19. Jacobs AH, Tavitian B, InMind Consortium. Noninvasive molecular imaging of neuroinflammation. Journal of Cerebral Blood Flow \& Metabolism. 2012; 32: 1393-415.

20. Chen MK, Guilarte TR. Translocator protein $18 \mathrm{kDa}$ (TSPO): molecular sensor of brain injury and repair. Pharmacol Ther. 2008; 118:1-17. 
21. Scarf AM, Kassiou M. The translocator protein. J Nucl Med. 2011; 52: 677-80.

22. Turner MR, Cagnin A, Turkheimer FE, Miller CC, Shaw CE, Brooks DJ, Leigh PN, Banati RB. Evidence of widespread cerebral microglial activation in amyotrophic lateral sclerosis: an $[11 \mathrm{C}](\mathrm{R})-\mathrm{PK} 11195$ positron emission tomography study. Neurobiol Dis. 2004; 15: 6019.

23. Corcia P, Tauber C, Vercoullie J, Arlicot N, Prunier C, Praline J, Nicolas G, Venel Y, Hommet C, Baulieu JL, Cottier JP, Roussel C, Kassiou M, Guilloteau D, Ribeiro MJ. Molecular imaging of microglial activation in amyotrophic lateral sclerosis. PLoS One. 2012; 7:e52941.

24. Zürcher NR, Loggia ML, Lawson R, Chonde DB, Izquierdo-Garcia D, Yasek JE, Akeju O, Catana C, Rosen BR, Cudkowicz ME, Hooker JM, Atassi N. Increased in vivo glial activation in patients with amyotrophic lateral sclerosis: assessed with [(11)C]-PBR28. Neuroimage Clin. 2015; 7: 409-14.

25. Venneti S, Wang G, Nguyen J, Wiley CA. The positron emission tomography ligand DAA1106 binds with high affinity to activated microglia in human neurological disorders. $\mathrm{J}$ Neuropathol Exp Neurol. 2008;67:1001-10.

26. Doorduin J, Klein HC, Dierckx RA, James M, Kassiou M, de Vries EF. [11C]- DPA-713 and [18F]-DPA-714 as new PET tracers for TSPO: a comparison with [11C]-(R)-PK11195 in a rat model of herpes encephalitis. Mol Imaging Biol. 2009; 11: 386-98.

27. Abourbeh G, Theze B, Maroy R, Dubois A, Brulon V, Fontyn Y, Dollé F, Tavitian B, Boisgard R. Imaging microglial/macrophage activation in spinal cords of experimental autoimmune encephalomyelitis rats by positron emission tomography using the mitochondrial $18 \mathrm{kDa}$ translocator protein radioligand $\left[{ }^{18} \mathrm{~F}\right] \mathrm{DPA}-714$. J Neurosci. 2012; 32: 5728-36.

28. Chauveau F, Van Camp N, Dollé F, Kuhnast B, Hinnen F, Damont A, Dollé F, Tavitian B. Comparative evaluation of the translocator protein radioligands 11C-DPA-713, 18F-DPA- 
714, and 11C-PK11195 in a rat model of acute neuroinflammation. J Nucl Med. 2009; 50: 468-76.

29. Martin A, Boisgard R, Theze B, Van Camp N, Kuhnast B, Damont A, Kassiou M, Tavitian B. Evaluation of the PBR/TSPO radioligand [(18)F]DPA-714 in a rat model of focal cerebral ischemia. J Cereb Blood Flow Metab. 2010; 30: 230-41.

30. Arlicot N, Vercouillie J, Ribeiro MJ, Tauber C, Venel Y, Baulieu JL, Maia S, Corcia P, Stabin MG, Reynolds A, Kassiou M, Guilloteau D. Initial evaluation in healthy humans of [18F]DPA-714, a potential PET biomarker for neuroinflammation. Nucl Med Biol. 2012; 39: $570-78$.

31. Vicidomini C, Panico M, Greco A, Gargiulo S, Coda AR, Zannetti A, Gramanzini M, Roviello GN, Quarantelli M, Alfano B, Tavitian B, Dollé F, Salvatore M, Brunetti A, Pappatà S. In vivo imaging and characterization of [18F]DPA-714, a potential new TSPO ligand, in mouse brain and peripheral tissues using small-animal PET. Nucl Med Biol. 2014; 42: 309-16.

32. Achilli F, Boyle S, Kieran D, Chia R, Hafezparast M, Martin JE, Schiavo G, Greensmith L, Bickmore W, Fisher EM. The SOD1 transgene in the G93A mouse model of amyotrophic lateral sclerosis lies on distal mouse chromosome 12. Amyotroph Lateral Scler. Other Motor Neuron Disord. 2005; 6: 111-14.

33. Solomon JA, Tarnopolsky MA, Hamadeh MJ. One Universal Common Endpoint in Mouse Models of Amyotrophic Lateral Sclerosis. PLoS One. 2011; 6: e20582.

34. Ludolph AC, Bendotti C, Blaugrund E, Chio A, Greensmith L, Loeffler JP, Mead R, Niessen HG, Petri S, Pradat PF, Robberecht W, Ruegg M, Schwalenstöcker B, Stiller D, van den Berg L, Vieira F, von Horsten S. Guidelines for preclinical animal research in ALS/MND: A consensus meeting. Amyotroph Lateral Scler. 2010; 11: 38-45.

35. Damont A, Hinnen F, Kuhnast B, Schöllhorn-Peyronneau M-A, James M, Luus C, Tavitian B, Kassiou M, Dollé F. Radiosynthesis of [18 F]DPA-714, a selective radioligand for 
imaging the translocator protein (18 kDa) with PET. J Label Comp Radiopharm. 2008; 51: 286-92.

36. Kuhnast B, Damont A, Hinnen F, Catarina T, Demphel S, Le Helleix S, Coulon C, Goutal S, Gervais P, Dollé F. [18 F]DPA- 714, [18 F]PBR111 and [18 F]FEDAA1106-selective radioligands for imaging TSPO $18 \mathrm{kDa}$ with PET: automated radiosynthesis on a TRACERLAb FX-FN synthesizer and quality controls. Appl Radiat Isot 2012;70:489-97.

37. Paxinos G, Franklin KB. The mouse brain in stereotaxic coordinates. San Diego: Elsevier Academic Press; 2001.

38. Cantarella G, Pignataro G, Di Benedetto G, Anzillotti S, Vinciguerra A, Cuomo O, Di Renzo GF, Parenti C, Annunziato L, Bernardini R. Ischemic tolerance modulates TRAIL expression and its receptors and generates a neuroprotected phenotype. Cell Death Dis. 2014; 5: e1331.

39. Autieri MV. cDNA cloning of human allograft inflammatory factor-1: tissue distribution, cytokine induction, and mRNA expression in injured rat carotid arteries. Biochem Biophys Res Commun 1996; 228: 29-37.

40. Ito D, Imai Y, Ohsawa K, Nakajima K, Fukuuchi Y, Kohsaka S. Microglia-specific localisation of a novel calcium binding protein, Iba1. Brain Res. Mol. Brain Res. 1998; 57: $1-9$.

41. Sasaki Y, Ohsawa K, Kanazawa H, Kohsaka S, Imai Y. Iba1 is an actin-cross-linking protein in macrophages/microglia. Biochem Biophys Res Commun. 2001; 286:292-297.

42. Siegel S, Castellan Jr. NJ. Nonparametric Statistics for the Behavioral Sciences. Second Edition, Sydney: McGraw Hill; 2000. p.143.

43. Nimchinsky EA, Young WG, Yeung G, Shah RA, Gordon JW, Bloom FE, Morrison JH, Hof PR. Differential vulnerability of oculomotor, facial, and hypoglossal nuclei in G86R superoxide dismutase transgenic mice. J Comp Neurol. 2000;416:112-25.

44. Zang DW, Yang Q, Wang HX, Egan G, Lopes EC, Cheema SS. Magnetic resonance 
imaging reveals neuronal degeneration in the brainstem of the superoxide dismutase 1 transgenic mouse model of amyotrophic lateral sclerosis. Eur J Neurosci. 2004;20:1745-51.

45. Angenstein F, Niessen HG, Goldschmidt J, Vielhaber S, Ludolph AC, Scheich H. Agedependent changes in MRI of motor brain stem nuclei in a mouse model of ALS. Neuroreport. 2004;15:2271-4.

46. Bucher S, Braunstein KE, Niessen HG, Kaulisch T, Neumaier M, Boeckers TM, Stiller D, Ludolph AC. Vacuolization correlates with spin-spin relaxation time in motor brainstem nuclei and behavioural tests in the transgenic G93A-SOD1 mouse model of ALS. Eur J Neurosci. 2007;26:1895-901.

47. Niessen HG, Angenstein F, Sander K, Kunz WS, Teuchert M, Ludolph AC, Heinze HJ, Scheich H, Vielhaber S. In vivo quantification of spinal and bulbar motor neuron degeneration in the G93A-SOD1 transgenic mouse model of ALS by T2 relaxation time and apparent diffusion coefficient. Exp Neurol. 2006;201:293-300

48. Evans MC, Serres S, Khrapitchev AA, Stolp HB, Anthony DC, Talbot K, Turner MR, Sibson NR. $\mathrm{T}_{2}$-weighted MRI detects presymptomatic pathology in the SOD1 mouse model of ALS. J Cereb Blood Flow Metab.2014;34:785-93.

49. An T, Shi P, Duan W, Zhang S, Yuan P, Li Z, Wu D, Xu Z, Li C, Guo Y. Oxidative stress and autophagic alteration in brainstem of SOD1-G93A mouse model of ALS. Mol Neurobiol. 2014; 49:1435-48.

50. Acquadro E, Caron I, Tortarolo M, Bucci EM, Bendotti C, Corpillo D. Human SOD1-G93A specific distribution evidenced in murine brain of a transgenic model for amyotrophic lateral sclerosis by MALDI imaging mass spectrometry. J Proteome Res. 2014; 13:1800-9.

51. Pagani M, Chiò A, Valentini MC, Öberg J, Nobili F, Calvo A, Moglia C, Bertuzzo D, Morbelli S, De Carli F, Fania P, Cistaro A. Functional pattern of brain FDG-PET in amyotrophic lateral sclerosis. Neurology. 2014; 83:1067-74.

52. Zang DW, Cheema SS. Degeneration of corticospinal and bulbospinal systems in the 
superoxide dismutase $1(\mathrm{G} 93 \mathrm{~A} \mathrm{G} 1 \mathrm{H})$ transgenic mouse model of familial amyotrophic lateral sclerosis. Neurosci Lett. 2002 ;332:99-102.

53. Muellauer J, Willimayer R, Goertzen AL, Wanek T, Langer O, Birkfellner W, Kuntner C. $18 \mathrm{~F}, 11 \mathrm{C}$ and $68 \mathrm{Ga}$ in small animal PET imaging. Evaluation of partial volume correction methods. Nuklearmedizin. 2013; 52: 250-61.

54. Kuper CF, Koornstra PJ, Hameleers DM, Biewenga J, Spit BJ, Duijvestijn AM, van Breda Vriesman PJ, Sminia T. The role of nasopharyngeal lymphoid tissue. Immunol Today. 1992; 13: $219-24$.

55. Lehnert W, Gregoire MC, Reilhac A, Meikle SR. Characterisation of partial volume effect and region-based correction in small animal positron emission tomography (PET) of the rat brain. Neuroimage. 2012; 60: 2144-57.

56. Hall ED, Oostveen JA, Gurney ME. Relationship of microglial and astrocytic activation to disease onset and progression in a transgenic model of familial ALS. Glia. 1998;23:249-56.

57. Alexianu ME, Kozovska M, Appel SH. Immune reactivity in a mouse model of familial ALS correlates with disease progression. Neurology. 2001;57:1282-9.

58. Graber DJ, Hickey WF, Harris BT. Progressive changes in microglia and macrophages in spinal cord and peripheral nerve in the transgenic rat model of amyotrophic lateral sclerosis. J Neuroinflammation. 2010; 28:7-8.

59. Papadimitriou D, Le Verche V, Jacquier A, Ikiz B, Przedborski S, Re DB. Inflammation in ALS and SMA: sorting out the good from the evil. Neurobiol Dis. 2010;37:493-502.

60. Caron I, Micotti E, Paladini A, Merlino G, Plebani L, Forloni G, Modo M, Bendotti C. Comparative Magnetic Resonance Imaging and Histopathological Correlates in Two SOD1 Transgenic Mouse Models of Amyotrophic Lateral Sclerosis. PLoS ONE 2015; 10: e0132159. 


\section{FIGURES}

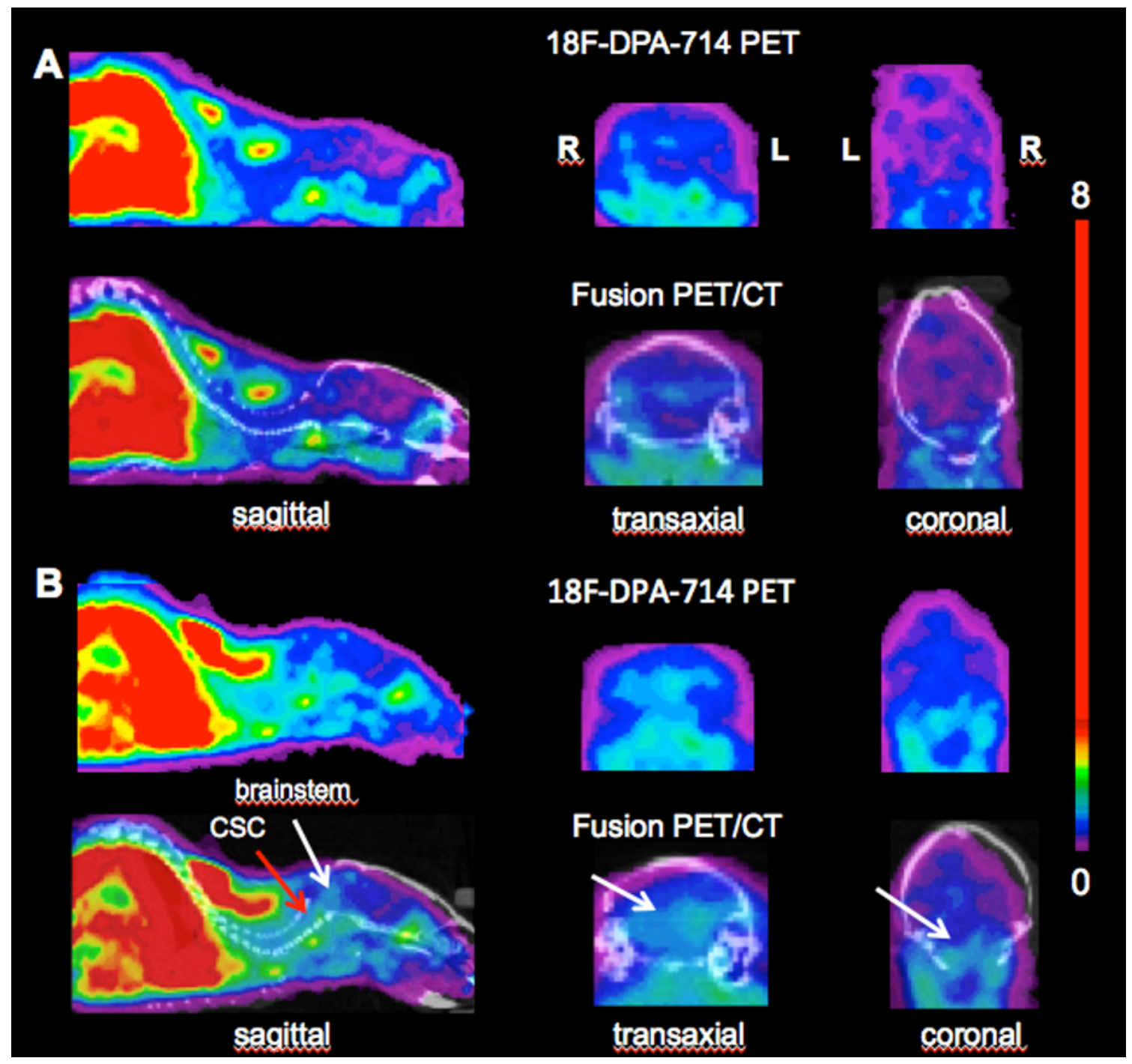

Fig. 1 Representative PET images obtained at the level of the brainstem in a WT SOD1 control (130 days old) (a) and in a symptomatic SOD $1^{\mathrm{G} 93 \mathrm{~A}}$ mouse (125-days old) with CS of 4 (b). The images were generated by summation of scans acquired between 20-50 minutes after the injection of ${ }^{18}$ F-DPA-714. The SUV values were normalized to those of the frontal association cortex and scaled at a maximum value of 8 . The images showed a clear increase of the ${ }^{18} \mathrm{~F}$-DPA-714 uptake in the brainstem of symptomatic SOD $1^{\mathrm{G} 93 \mathrm{~A}}$ mouse (white arrow) as compared to WT SOD1 control. The sagittal PET-CT fusion images also showed an increased uptake in the cervical spinal cord of symptomatic SOD1 ${ }^{\mathrm{G} 93 \mathrm{~A}}$ mouse (red arrow). Accumulation of ${ }^{18} \mathrm{~F}-\mathrm{DPA}-714$ in the Harderian glands of SOD $1^{\mathrm{G} 93 \mathrm{~A}}$ mouse was evident. $\mathrm{R}$ and $\mathrm{L}$ indicate right and left side of animals, respectively 


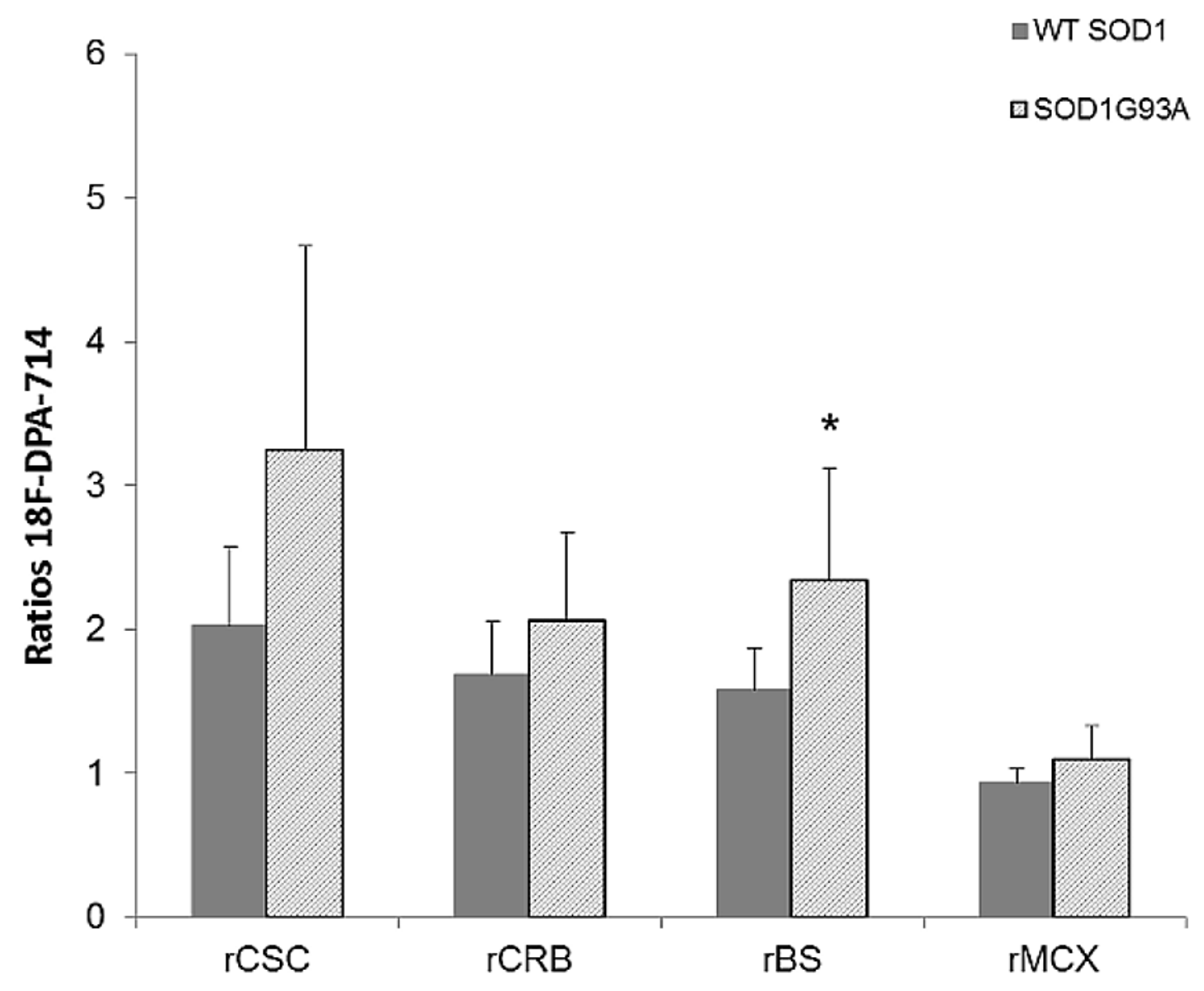

Fig. 2 The histogram shows the mean \pm SD of the ${ }^{18}$ F-DPA-714 SUV ratios to the frontal association cortex in cervical spinal cord (rCSC), cerebellum (rCRB), brainstem (rBS) and motor cortex (rMCX) of WT SOD1 controls and of symptomatic SOD $1^{\mathrm{G} 93 \mathrm{~A}}$ mice. The brainstem revealed a significant increase of the ${ }^{18} \mathrm{~F}-\mathrm{DPA}-714$ uptake in symptomatic SOD ${ }^{\mathrm{G} 93 \mathrm{~A}}$ mice $(*=\mathrm{p}<0.02)$ 
a)

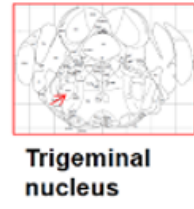

nucleus
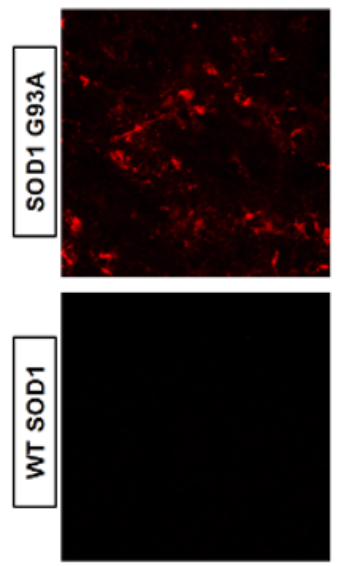

b)

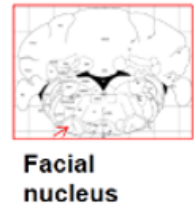

nucleus
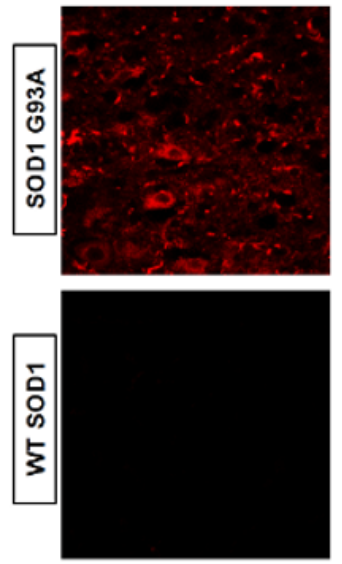

c)

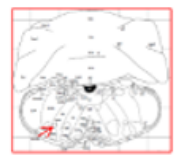

Ambiguus nucleus
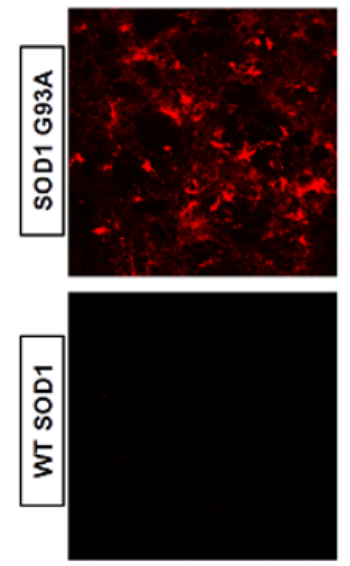

d)

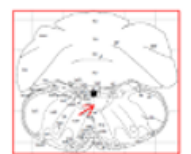

Hypoglossal nucleus
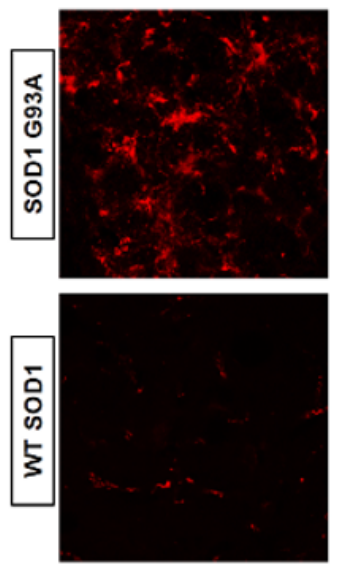

Iba1
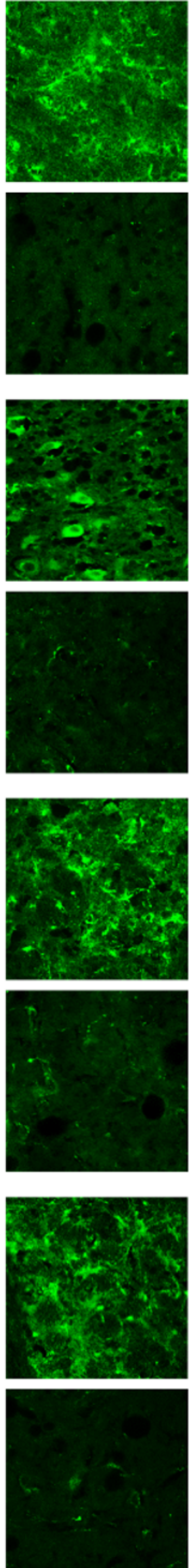

TSPO + Iba1
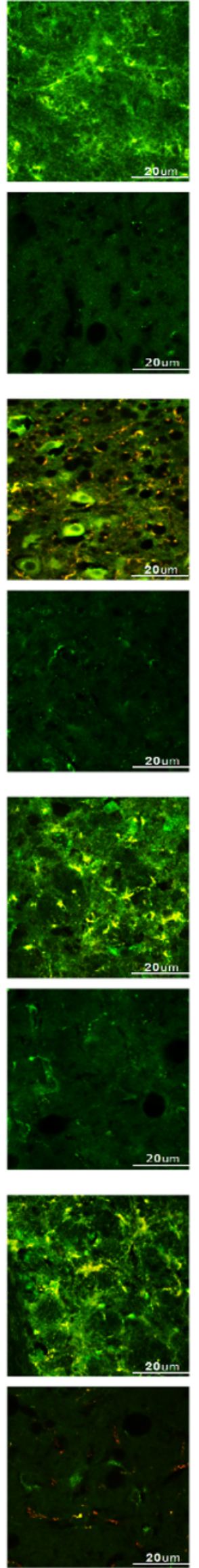
Fig. 3 Representative confocal laser scanning microscopy images of double-label immunofluorescence for TSPO and microglia in the trigeminal nucleus (a), facial nucleus (b), ambiguus nucleus (c) and hypoglossal nucleus (d) in a symptomatic SOD $1^{\mathrm{G} 93 \mathrm{~A}}$ mouse (125-dayold) with CS of 4 and in a WT SOD1 control (130-days-old). TSPO immunolabeling (visualized in red-cy3 immunofluorescence), Iba1 immunolabeling (visualized in green-cy2 immunofluorescence) and merged images (TSPO+Ibal visualized in orange). The images show a strong increase of TSPO and Iba1 immunoreactivities in all brainstem nuclei in symptomatic SOD1 ${ }^{\mathrm{G} 93 \mathrm{~A}}$ mouse compared to WT SOD1 control. In the facial nucleus, Iba1 positive cells show a dramatic morphological change that includes enlargement of the cell body and shortening of cellular processes. Merged image reveal that the TSPO distribution colocalized with Iba1 positive cells. Scale bar: $20 \mu \mathrm{m}$ 
TSPO

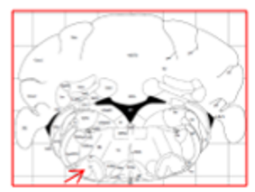

Facial nucleus
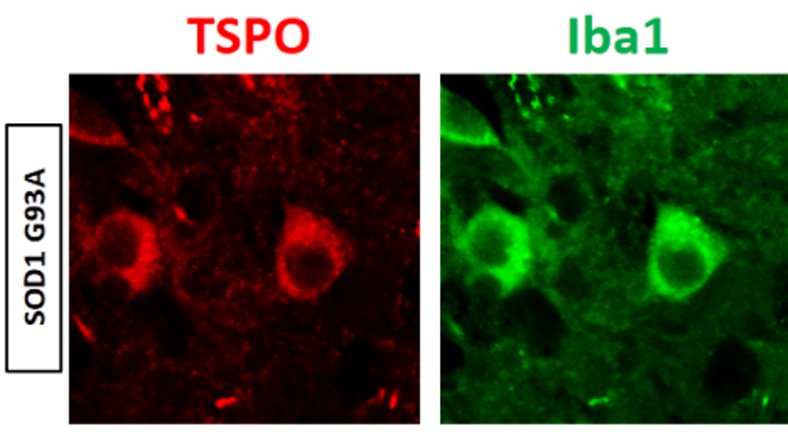

TSPO + Iba1
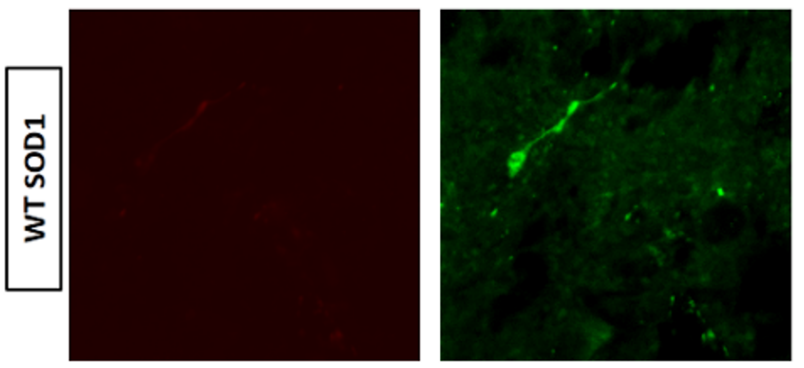
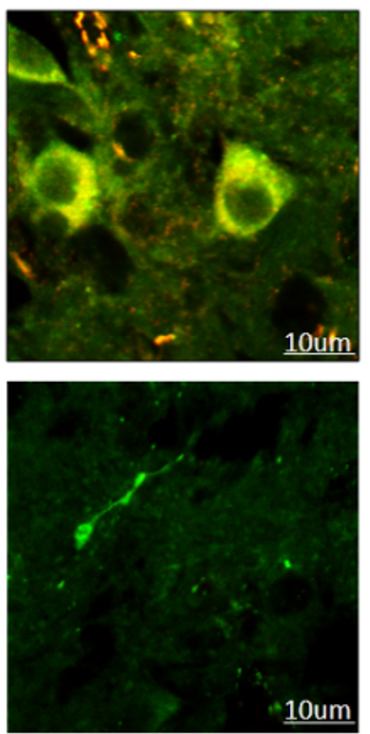

Fig. 4 Representative high magnification (63X) of confocal laser scanning microscopy images of double-label immunofluorescence for TSPO and microglia in facial nucleus in a symptomatic SOD $1^{\mathrm{G} 93 \mathrm{~A}}$ mouse (125-day-old) with CS of 4 and in a WT SOD1 control (130-days-old). TSPO immunolabeling (visualized in red-cy3 immunofluorescence), Iba1 immunolabeling (visualized in green-cy2 immunofluorescence) and merged images (TSPO+Ibal visualized in orange). The images showed a clear morphological change of Ibal positive cells, with enlarged body shape and short cellular processes. Scale bar: $10 \mu \mathrm{m}$ 
a)

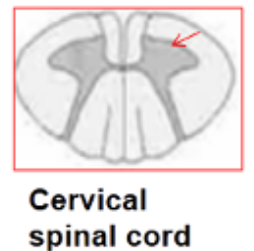

spinal cord
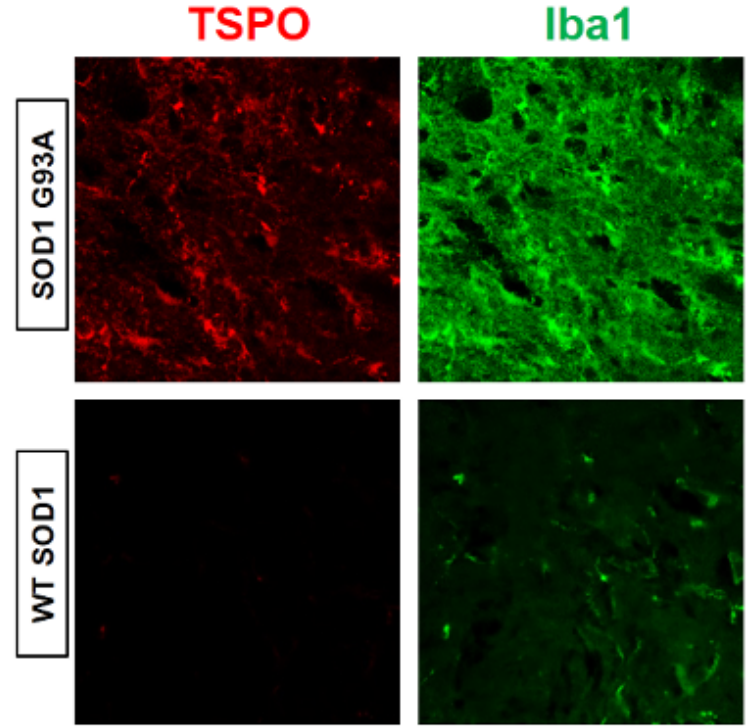

TSPO + Iba1

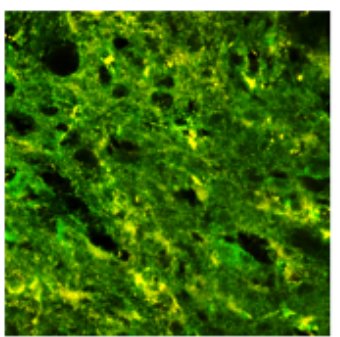

b)

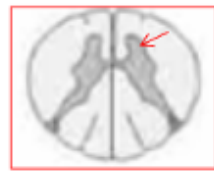

Thoracic

spinal cord
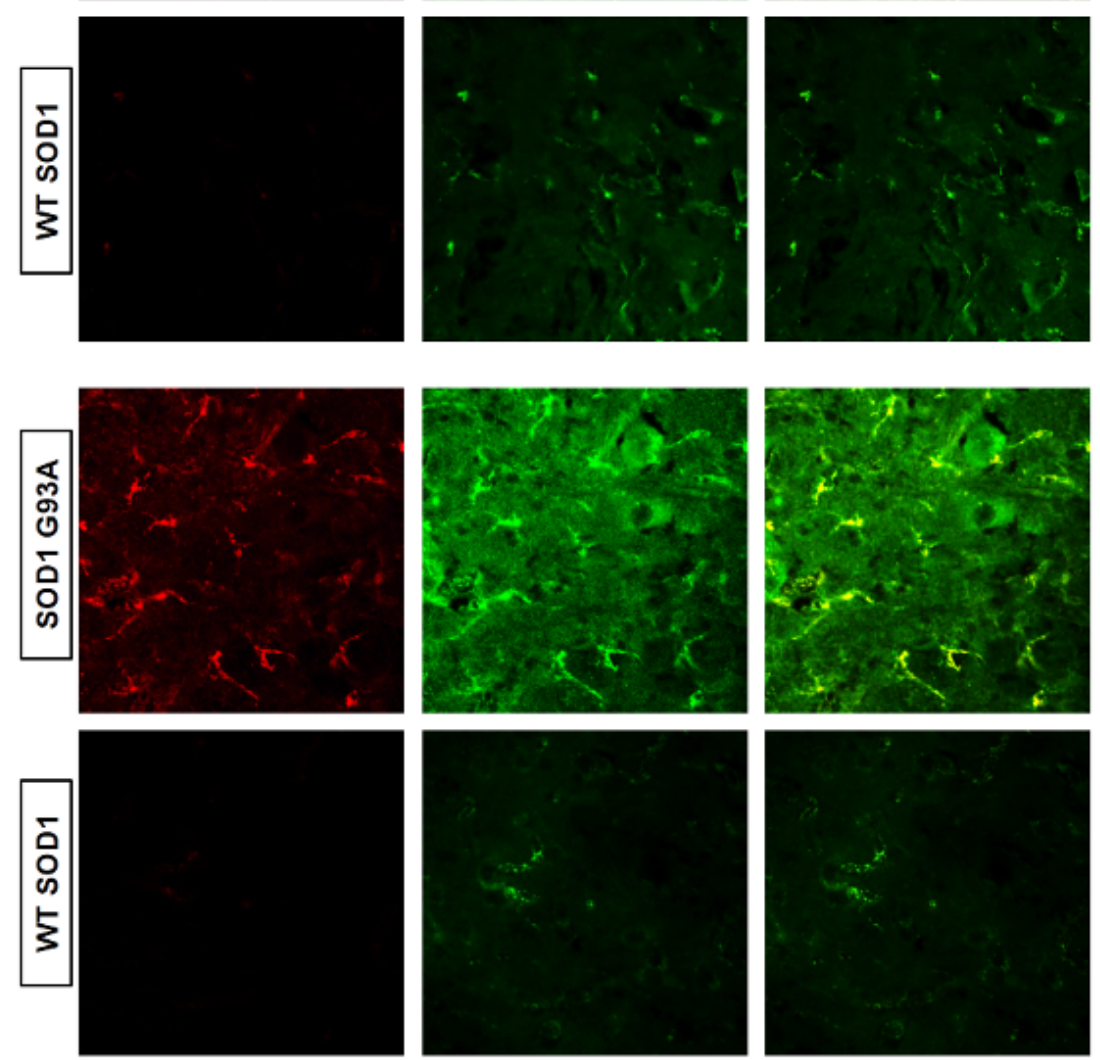

c)
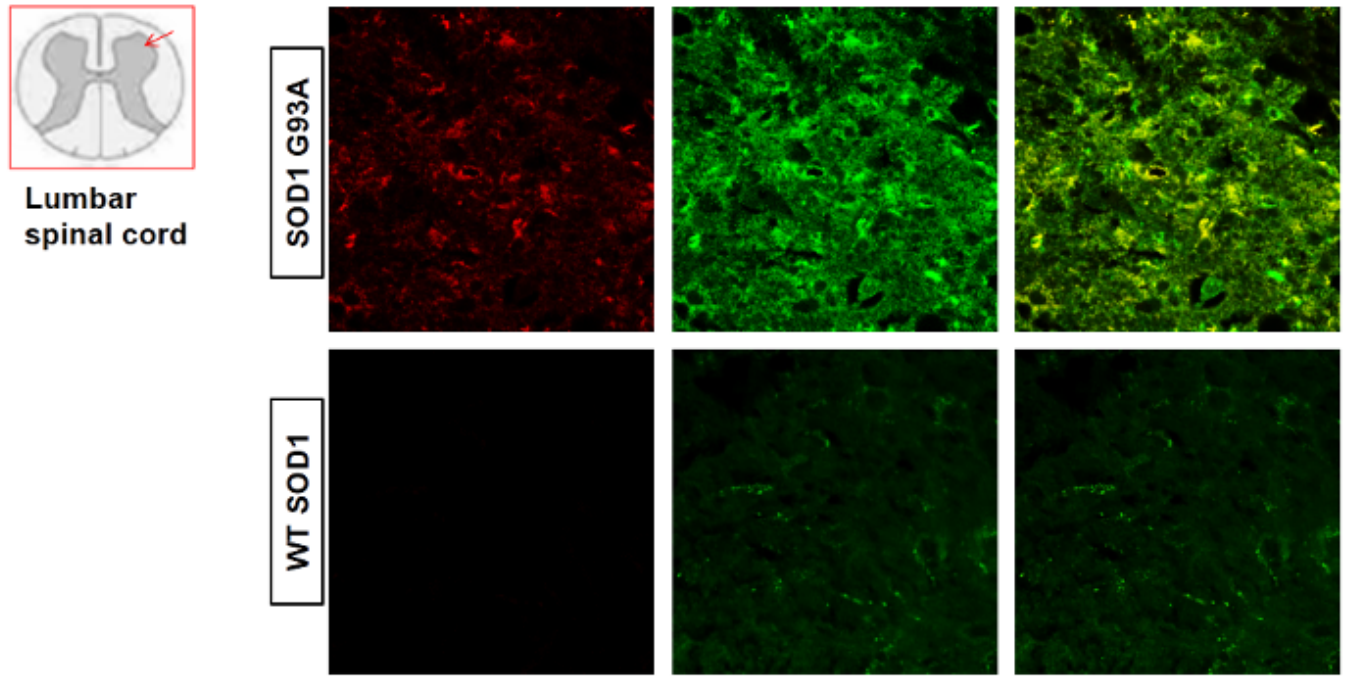
Fig. 5 Representative confocal laser scanning microscopy images of double-label immunofluorescence for TSPO and microglia in the cervical (a), thoracic (b) and lumbar (c) spinal tracts in a symptomatic SOD $1^{\mathrm{G} 93 \mathrm{~A}}$ mouse (125-day-old) with CS of 4 and in a WT SOD1 control (130-days-old). TSPO immunolabeling (visualized in red-cy3 immunofluorescence), Iba1 immunolabeling (visualized in green-cy2 immunofluorescence) and merged images (TSPO+Iba1 visualized in orange). Increased TSPO expression and Ibal immunolabeling can be observed in all the spinal tracts. Merged images showed a colocalization of TSPO and Iba1 immunoreactivities. Scale bar: $20 \mu \mathrm{m}$ 


\section{Supplementary Figures}

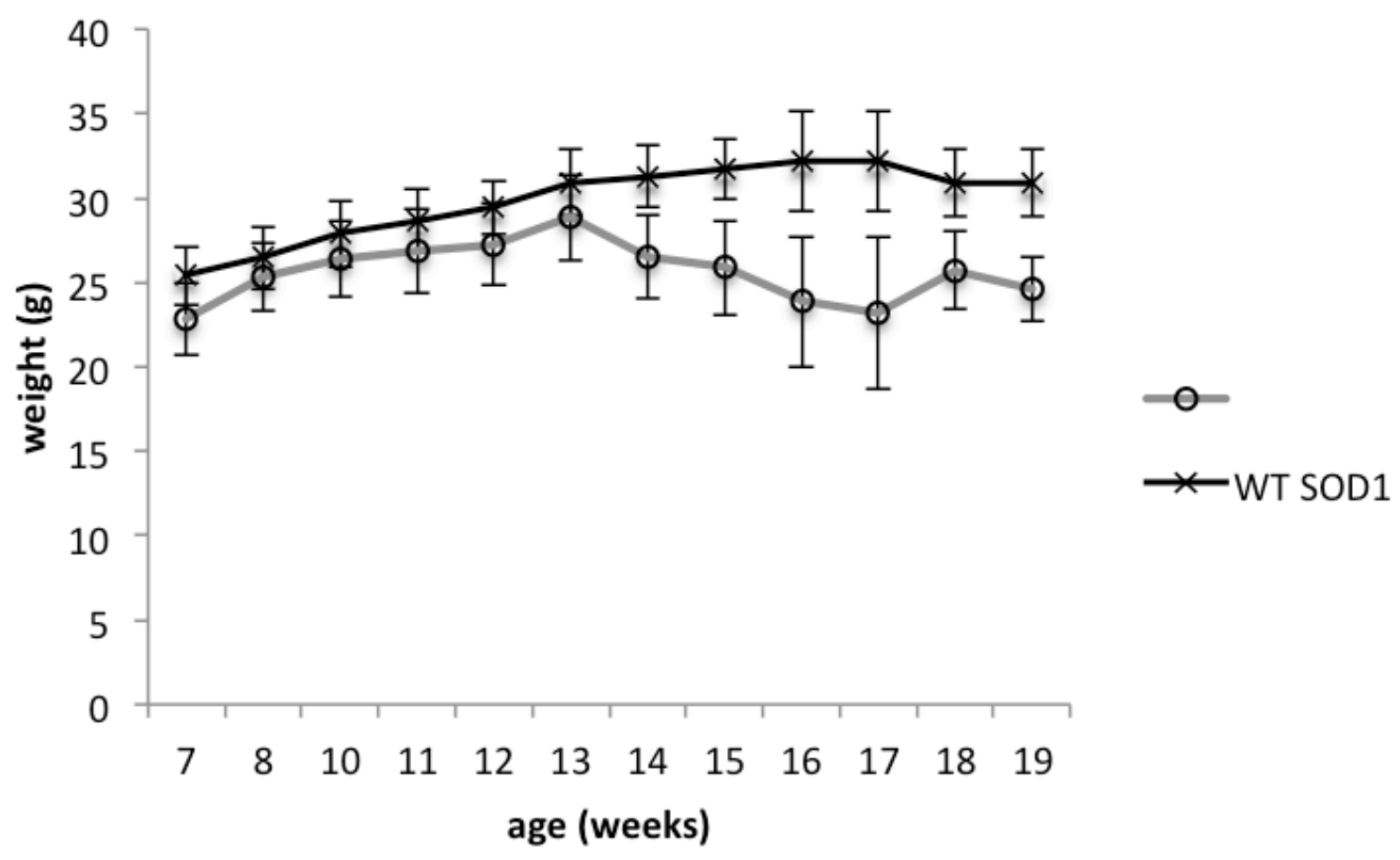

Supplementary Fig. 1 Body weight (mean \pm SD) registered from 7 to 19 weeks of age in SOD1 ${ }^{\text {G93A }}$ and WT SOD1 mice 


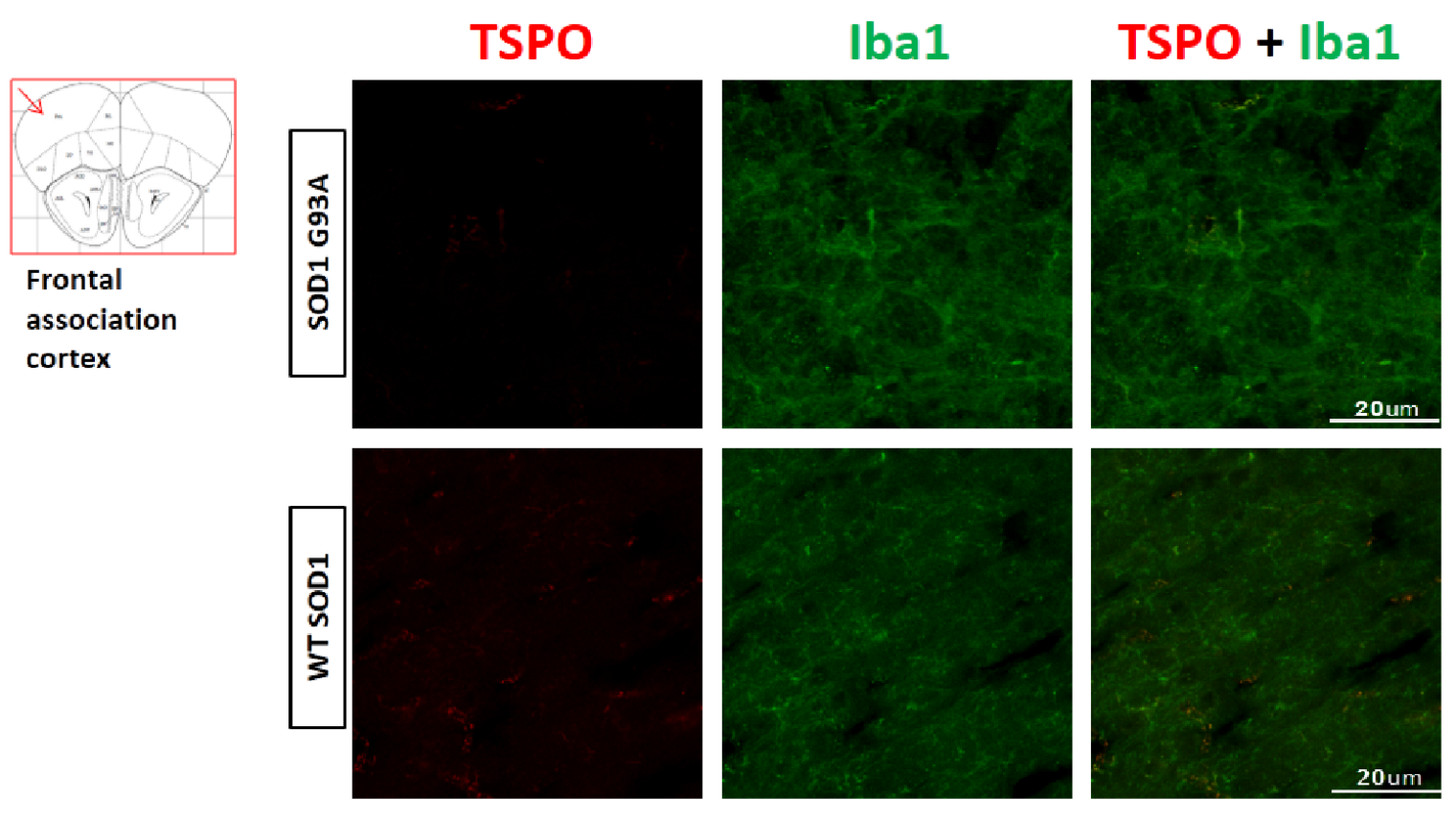

Supplementary Fig. 2 Representative confocal laser scanning microscopy images of double-label immunofluorescence for TSPO and microglia in the frontal association cortex in a symptomatic SOD $1^{\mathrm{G} 93 \mathrm{~A}}$ mouse (125-day-old) with CS of 4 and in a WT SOD1 control (130-days-old). TSPO immunolabeling (visualized in red-cy3 immunofluorescence), Iba1 immunolabeling (visualized in green-cy2 immunofluorescence) and merged images (TSPO+Ibal visualized in orange). The images show the absence of TSPO and Ibal immunoreactivities both in symptomatic SOD1 ${ }^{\mathrm{G} 93 \mathrm{~A}}$ mouse and WT SOD1 control. Scale bar: $20 \mu \mathrm{m}$ 


\begin{tabular}{|l|c|c|}
\hline \multicolumn{1}{|c|}{ CNS } & SOD1 ${ }^{\mathrm{G} 93 \mathrm{~A}}$ & WT SOD1 \\
\hline $\boldsymbol{M C X} \boldsymbol{C}$ & & \\
\hline $\boldsymbol{B S}$ & $1.090 \pm 0.242$ & $0.928 \pm 0.101$ \\
\hline $\boldsymbol{C R B}$ & $2.340 \pm 0.784^{*}$ & $1.576 \pm 0.287^{*}$ \\
\hline $\boldsymbol{C S C}$ & $2.063 \pm 0.612$ & $1.691 \pm 0.364$ \\
\hline
\end{tabular}

Table 1. SUV ratios measured in different CNS regions (mean \pm SD) of the SOD1G93A and WT SOD1 mice Legend: motor cortex (MCX), brainstem (BS), cerebellum (CRB), cervical spinal cord (CSC). SUV ratios were calculated by normalizing the activity of the different regions to that of the frontal association cortex (FrA). ${ }^{*} \mathrm{p}<0.05$. 